\title{
Comunicação do Diagnóstico de Câncer: Análise do Comportamento Médico
}

Cancer Diagnosis Communication: Analysis of the Physician Behavior

\author{
Cláudio Henrique Rebello Gomes', Patrícia Veloso Silva², Fernando Freitas Mota²
}

\section{Resumo}

Introdução: o diagnóstico de câncer deixa de ser comunicado aos pacientes em grande parte das vezes, o que gera uma série de discussões na área da ética médica. Objetivo: analisar a conduta de médicos especialistas em oncologia e não especialistas quanto à comunicação do diagnóstico de câncer, bem como abordar as questôes éticas relacionadas a esse contexto. Métodos: os autores avaliaram, de maneira prospectiva, 396 pacientes e seus familiares encaminhados por 76 médicos para ambulatório especializado de cirurgia oncológica, no período de 2002 a 2006. Resultados: duzentos e noventa e um pacientes eram do sexo feminino e 105 do sexo masculino. Em relação à topografia da lesão, a maioria encontrava-se no abdômen ou pelve (86\%), sendo $9 \%$ dos tumores originados na região da cabeça e pescoço, $4 \%$ em tórax e $1 \%$ em membros. O índice de omissão do diagnóstico foi de $28,5 \%$. Os médicos não especialistas deixaram de informar a $87,9 \%$ dos seus pacientes, enquanto que os especialistas omitiram o diagnóstico em $6,4 \%$ dos casos. Os familiares dos doentes não informados foram comunicados somente em $27,4 \%$ das vezes. Em 14,2\% dos casos, foi solicitado pelos familiares em pré-consulta no ambulatório que o paciente não tomasse conhecimento da neoplasia. Conclusão: a taxa de omissão das informações foi superior entre os médicos não especialistas, porém não foi nula entre aqueles que trabalham habitualmente com o câncer.

Palavras-chave: Barreiras de comunicação; Diagnóstico clínico; Neoplasias; Ética médica

${ }^{1}$ Cirurgiāo oncológico. Coordenador do grupo de Cirurgia Oncológica do UNACOM Dílson de Quadros Godinho. Docente da Universidade Estadual de Montes Claros (Unimontes), MG

${ }^{2}$ Acadêmicos do curso de Medicina da (Unimontes), MG

Enderę̧o para correspondência: E-mail: patriciavelososilva@yahoo.com.br 


\section{INTRODUÇÃO}

Apesar de todos os avanços científicos e tecnológicos alcançados na Medicina, o câncer ainda é uma doença estigmatizante ${ }^{1}$. Tanto para muitos profissionais médicos quanto para o doente e sua família o diagnóstico de câncer continua sendo uma sentença de morte.

Pouca ênfase tem sido direcionada ao treinamento de habilidades e técnicas em comunicação e avaliação do fator psicossocial, requisitos essenciais para um atendimento adequado de pacientes oncológicos. Os profissionais dependem então de sua experiência e julgamento pessoais em relação à decisão de informar ao paciente sobre sua doença, bem como sobre a melhor maneira de comunicar e em que momento fazê-lo ${ }^{1}$.

A falta de preparo dos médicos faz com que os doentes sejam muitas vezes colocados à margem do seu diagnóstico e das opções de tratamento, inclusive sendolhes negado o direito de escolha entre possibilidades terapêuticas e sua inserção em grupos de cuidados paliativos que comprovadamente proporcionam melhoria na sua qualidade de vida.

A comunicação do diagnóstico ao paciente é dever do médico e está prevista em seu código de ética profissional ${ }^{2}$. A não comunicação só é permitida em casos de pacientes pediátricos, ou quando suas condições físicas ou psicológicas não permitam uma correta compreensão de sua doença ${ }^{3}$, devendo nesse caso ser o diagnóstico comunicado à família ou responsável. É, pois, uma conduta de exceção e exige do profissional discernimento e envolvimento suficientes para saber reconhecer para quais pacientes a verdade pode ser omitida.

O objetivo deste estudo foi analisar a conduta de médicos especialistas e não especialistas em relação à comunicação do diagnóstico de câncer e abordar as questôes éticas relacionadas a esse contexto.

\section{METODOLOGIA}

Foram analisados, de maneira prospectiva, 396 pacientes com câncer, encaminhados por 76 médicos para ambulatório especializado de Oncologia Cirúrgica, já com diagnóstico estabelecido e com comprovação histológica. Os relatos dos familiares desses pacientes também foram incluídos na análise.

Os dados foram obtidos durante as entrevistas médicas, realizadas sempre pelo mesmo profissional, no período de setembro de 2002 a outubro de 2006. Os pacientes e seus familiares consentiram com o registro e utilização dos dados para a produção e publicação deste estudo, o qual foi avaliado e autorizado pela Comissão de Ensino e Pesquisa do Hospital Dilson de Quadros Godinho.
Os pacientes foram avaliados no primeiro atendimento e questionados diretamente se eram conhecedores do seu diagnóstico. Tal questionamento foi realizado na presença do familiar que estava presente no dia da consulta. Em todos os casos em que os pacientes negaram ter sido informados, houve confirmação desse relato por parte dos familiares. As informações relacionadas ao diagnóstico foram discutidas com o paciente de maneira clara e direta, considerando o perfil psicossocial de cada um, respeitando, inclusive, o direito do paciente de recusar a se submeter à intervenção proposta.

Os médicos que realizaram os encaminhamentos foram classificados em dois grupos: especialistas, considerados aqueles que trabalham habitualmente com a cancerologia (cirurgiōes oncológicos, radioterapeutas e oncologistas clínicos); e não especialistas, no qual foram incluídos os médicos que não estão ligados diretamente a essa área (clínicos gerais, médicos de família, cirurgiōes gerais).

Outros fatores avaliados foram: número de consultas realizadas antes do encaminhamento, pressupondo-se que o maior número de consultas propiciaria maior possibilidade de comunicação; idade dos pacientes, pela tendência cultural de se preservar os idosos de tais informaçōes; e reação da família frente à necessidade de se discutir sobre a doença de maneira aberta com o paciente.

Foram excluídos da análise os médicos que tiveram contato com o paciente apenas para a realização de algum tipo de propedêutica, como exames de imagem, endoscopias ou biópsias.

\section{RESULTADOS}

Do total de 396 pacientes, 291 eram do sexo feminino $(73,5 \%)$ e 105 do sexo masculino (26,5\%). O índice de omissão do diagnóstico foi de 28,5\% (113 pacientes), sendo que em 94 casos a não comunicação ocorreu entre os médicos não especialistas (grupo B). Entre os médicos especialistas (grupo A), a verdade foi comunicada a 270 pacientes $(93,4 \%$, versus $12,1 \%$ no grupo $B)$, ao passo que a omissão ocorreu em 19 casos $(6,6 \%$, versus $87,9 \%$ no grupo B). Dos pacientes que não foram informados, 94 (83\%) já suspeitavam que eram portadores de doença maligna. Os familiares dos doentes não informados foram comunicados somente em 31 casos $(27,4 \%)$ e, em 16 vezes $(14,2 \%)$, solicitaram em pré-consulta no ambulatório que o paciente não tomasse conhecimento da neoplasia.

Em relação à topografia da lesão, a maioria encontrava-se no abdômen ou pelve $(87,9 \%)$, sendo $0,9 \%$ dos tumores originados na região da cabeça e pescoço, $0,3 \%$ em tórax e em $0,1 \%$ nos membros (tabela 1 ). 
Tabela 1. Topografia da Neoplasia

\begin{tabular}{c|c|c|c|}
\hline $\begin{array}{c}\text { Topografia da } \\
\text { neoplasia }\end{array}$ & $\begin{array}{c}\mathbf{N}^{\circ} \text { de pacientes } \\
\text { informados }\end{array}$ & $\begin{array}{c}\mathbf{N}^{\circ} \text { de pacientes não } \\
\text { informados }\end{array}$ & $\begin{array}{c}\text { Total } \\
\text { Abdômen/pelve }\end{array}$ \\
Cabeça e pescoço & 242 & 99 & 341 \\
Tórax & 30 & 7 & 36 \\
Membros & 8 & 1 & 4 \\
\hline
\end{tabular}

Quanto ao número de consultas realizadas antes do encaminhamento, a média foi de cinco entre os pacientes comunicados e de dois entre os não comunicados.

Os pacientes informados tinham média de idade de 55,6 anos na ocasião do encaminhamento, enquanto que os não informados tinham média de 58,5 anos.

\section{DISCUSSÃO}

Para Pessini ${ }^{5}$, "a veracidade é o fundamento da confiança nas relações interpessoais". Tendo como fundamento os princípios da Bioética, pode-se dizer que a comunicação da verdade diagnóstica ao paciente e seus familiares constitui um benefício para os mesmos (princípio da beneficência), pois possibilita sua participação ativa no processo de tomada de decisōes (autonomia) ${ }^{5}$.

Em algumas situações, a efetivação dessa comunicação não é fácil, principalmente quando se trata de notícias ruins, como o diagnóstico de enfermidades progressivas que são consideradas algumas vezes, por médicos e pacientes, como incuráveis.

Neste trabalho, obteve-se um índice de omissão do diagnóstico de $28,5 \%$, o que condiz com a afirmação de Kovács ${ }^{6}$ de que os profissionais da área de saúde não foram adequadamente preparados para lidar com a possibilidade da morte, sendo esta um processo natural do adoecimento e próprio da vida humana.

Se a doença se agrava e a morte se aproxima, é comum surgirem sérios distúrbios de comunicação, conhecidos como "conspiração do silêncio"7, em que o médico assume uma postura falsamente paternalista que o leva a ocultar a verdade do paciente ${ }^{5}$.

Percebeu-se que essa atitude foi mais frequente em meio aos médicos não especialistas $(87,9 \%)$, embora não tenha sido nula entre os médicos especialistas $(6,6 \%)$. $\mathrm{O}$ maior número médio de consultas pré-comunicação realizadas com os médicos especialistas nos faz refletir se $6,6 \%$ de não comunicação seria ainda um número excessivamente alto. Foi considerada para análise desses dados somente a informação do paciente e familiar, não sendo possível neste estudo identificar aqueles que foram informados e negaram esse fato na primeira entrevista.

Ao omitir a verdade do paciente, o médico também contraria o seu código de ética ${ }^{2}$, nos artigos 41, 46, 48 e 59. Neste último, por exemplo, consta que é vedado ao médico: "Deixar de informar ao paciente o diagnóstico, o prognóstico, os riscos e objetivos do tratamento, salvo quando a comunicação direta ao mesmo possa provocar-lhe dano, devendo, nesse caso, a comunicação ser feita ao seu responsável legal"2.

De acordo com Fitch ${ }^{8}$, os pacientes com doença progressiva e incurável precisam compreender o que está acontecendo consigo e com seus corpos. "Eles precisam participar dos processos de tomada de decisão sobre como vão viver os dias remanescentes"8.

Acredita-se que, especialmente na área da cancerologia, o esclarecimento a respeito das possibilidades terapêuticas deve envolver um diálogo aberto entre o médico e o paciente, tendo em vista a necessidade de realizar procedimentos mutilantes, que muitas vezes são a única chance de cura para aquele doente. E, mesmo quando não houver possibilidade de cura, o paciente deve ser orientado em relação aos tratamentos paliativos aos quais poderá ser submetido, esclarecendo sobre os benefícios dos mesmos para a melhora de sua qualidade de vida.

Os pacientes, quando questionados, consideraram muito importante ter acesso às informaçóes sobre as condições de seus corpos, suas doenças, opçōes de tratamento e efeitos adversos dos tratamentos ${ }^{8}$.

Ao omitir o diagnóstico de câncer, o profissional está exercendo sua autoridade em detrimento da opção do paciente de querer sabê-lo. Isso demonstra um antigo preconceito que se tem em relação aos pacientes oncológicos: a ideia de que os mesmos não gostariam de saber qual é a sua doença. Renata Novaes Pinto ${ }^{9}$, em uma pesquisa realizada com 298 pacientes, mostra que essa não é a realidade, já que $95 \%$ dos entrevistados afirmaram que gostariam de receber informação sobre sua doença, principalmente em caso de câncer.

Neste trabalho, percebeu-se que, mesmo quando se optou por não revelar o diagnóstico de câncer, a maioria dos pacientes $(83 \%)$ afirmou que já suspeitava do mesmo. Não poderia se esperar algo diferente, já que 
as evidências para o diagnóstico passam a ser constantes na vida do doente. Ele o percebe enquanto aguarda atendimento em uma fila onde só há pessoas com câncer e que estão, não raro, em um hospital que possui em seu nome a palavra câncer, ou mesmo quando é submetido a procedimentos terapêuticos que são conhecidamente direcionados à oncologia, quando é encaminhado a um médico especialista na área, quando os seus familiares comentam pelos cantos em voz baixa, além dos próprios sintomas da doença que passam a se manifestar, como emagrecimento e dor.

Para que a comunicação da verdade seja moralmente boa, deve-se prestar atenção a $o$ que, como, quando, quanto, quem e a quem se deve informar. Claro, exigese muita prudência. Com frequência, a mentira e a evasão são os que mais isolam os pacientes atrás de um muro de palavras ou de silêncio e impede-os de aceitar o benefício terapêutico de partilhar os medos, as angústias e as preocupações. Não é possível praticar a medicina paliativa sem um compromisso prévio de abertura e honestidade para com a verdade dos fatos. Deve-se dar uma resposta honesta aos pacientes que desejam saber de sua condição de vida, bem como assegurá-los de que aqueles que ficam, seus familiares, estarão bem, apesar da dor do luto5.

As pessoas doentes sabem, ou intuem, o que está acontecendo com elas, mesmo que não sejam informadas diretamente. Não contar, ou fingir que nada está acontecendo, favorece que se crie uma situação de fingimento, que muitas vezes é mútua. Há a transmissão de mensagens ambivalentes, em que o conteúdo verbal expresso, de que está tudo bem, não coincide com as informações trazidas por semblantes carregados e olhos vermelhos, sinalizando o agravamento da situação. $\mathrm{O}$ conteúdo verbal pode ser censurado, mas é virtualmente impossível controlar todos os movimentos, os gestos e as expressóes corporais. O paciente, preocupado com o que percebe em si, busca nas pessoas à sua volta a confirmação de suas impressões. Nesse momento, podese instalar um sentimento de isolamento, porque não está ocorrendo uma comunicação de fato ${ }^{6}$.

Vale dizer que comunicar uma notícia não é simplesmente informar e desaparecer. Trata-se de um processo que leva tempo e que deve ser realizado em várias etapas. Sabe-se que algumas informações terão de ser dadas repetidas vezes, já que pessoas em grave impacto emocional geralmente não absorvem aquilo que ouvem ${ }^{6}$, mesmo que a linguagem utilizada seja compreensível.

Considerações como essas deixam claro que a não comunicação do diagnóstico ao paciente deve ser uma conduta de exceção. Infelizmente, o que nota-se em nossa série é que a mesma tornou-se regra, principalmente em meio aos médicos não especialistas (87,9\% de omissão no grupo B versus $6,6 \%$ no grupo $\mathrm{A})$.

No artigo 59 do código de ética médica, consta que, nos casos em que o diagnóstico, o prognóstico e os riscos não forem comunicados ao paciente, devem ser feitos ao seu responsável, o que não aconteceu na maioria das vezes $(72,6 \%)$.

Considerar que a não comunicação é uma conduta para "preservar" o doente é menosprezar a realidade dos fatos. Muitas vezes o real objetivo é a proteção do médico que se vê impotente diante de suas limitações em "curar", inseguro em orientar e despreparado em "cuidar". Passa a se angustiar e sofrer como o paciente e família, com a diferença que tem a opção da fuga, abandonando de formas variadas o doente.

\section{CONCLUSÃO}

A comunicação do diagnóstico ao paciente é dever do médico; porém, quando se trata de câncer, os profissionais apresentam dificuldades em dialogar abertamente com os doentes. A taxa de omissão das informações foi superior entre os médicos não especialistas; porém não foi nula entre aqueles que trabalham habitualmente com o câncer.

Eu me importo pelo fato de vocês ser você, me importo até o último momento de sua vida e faremos tudo o que está ao nosso alcance, não somente para ajudar você a morrer em paz, mas também para você viver até o dia da morte.

Hennezel e Leloup ${ }^{10}$

\section{Potencial Conflito de Interesses: Nada a Declarar}

\section{REFERÊNCIAS}

1. Cavalcanti DR. Comunicação do diagnóstico de doença grave (câncer) ao paciente: Quem? Quando? Como? Por quê? PanAmerican Family Medicine Clinics 2005;1:41-5.

2. Conselho Federal de Medicina (CFM). Código de ética médica. Brasília: Diário Oficial da União;1988. p. 1574-7.

3. Sprosser JG, Araújo ME. Papel do cirurgiāo dentista frente ao diagnóstico positivo de câncer de boca. In: Genovese WJ. Câncer de boca: noções básicas para prevenção e diagnóstico. São Paulo: Fundação Petrópolis; 1997.

5. Pessini L. Bioética e cuidados paliativos: alguns desafios do cotidiano aos grandes dilemas. In: Pimenta CAM, Mota DDCF, Cruz DALM. Dor e cuidados paliativos: enfermagem, medicina e psicologia. 1. ed. Barueri, SP: Manole; 2006.

6. Kovács MJ. Comunicação em cuidados paliativos. In: Pimenta CAM, Mota DDCF, Cruz DALM. Dor e cuidados 
paliativos: enfermagem, medicina e psicologia. 1 ed. Barueri, SP: Manole; 2006.

7. Kovács MJ. Morte e desenvolvimento humano. São Paulo: Casa do Psicólogo; 1992.

8. Fitch MI. Necessidades emocionais de pacientes e cuidadores em cuidados paliativos. In: Pimenta CAM, Mota DDCF, Cruz DALM. Dor e cuidados paliativos: enfermagem, medicina e psicologia. 1. ed. Barueri, SP: Manole; 2006.

9. Pinto RN. A comunicação do diagnóstico no paciente com câncer [dissertação]. São Paulo: Universidade Federal de São Paulo (Unifesp); 2001.

10. Hennezel M, Leloup JY. A arte de morrer: tradições religiosas e espiritualidade humanística diante da morte na atualidade. Petrópolis, RJ: Vozes; 1999.

\section{Abstract}

Introduction: cancer diagnosis is not often communicated to the patients most of the time, which generates a series of discussions in the area of medical ethics. Objective: to examine the conduct of medical specialists in oncology and with non-specialists, when the communication of the cancer diagnosis, and to address the ethical issues related to this context. Methods: the authors assessed, in a prospective manner, 396 patients and their families referred by 76 physicians to specialized emergency surgery clinics for cancer from the period of 2002 to 2006. Results: two hundred and ninety one patients were female and one hundred and five were male. In relation to the topography of the lesion, most of them were in the abdomen or pelvis (86\%), and $9 \%$ of the tumors originated in the head and neck, $4 \%$ in the thorax and $1 \%$ in members. The diagnosis omission index was $28.5 \%$. Non-specialist doctors did not inform $87.9 \%$ of their patients, while the specialized doctors omitted the diagnosis in $6.4 \%$ of the cases. Family members of the non-informed patients were only communicated $27.4 \%$ of the time. $14.2 \%$ of cases, family members complained, before visiting, that patient was not aware of the neoplasia. Conclusion: the omission index of information was higher between non-specialist doctors; but, it was not zero between those who usually work with the cancer.

Key words: Communication barriers; Diagnosis, clinical; Neoplasms; Ethics, medical 